\title{
A project of harmonious health renewal in psychoneurological patients on the basis of the personalized algorithms for treatment and rehabilitation
}

\author{
Ulyana B Lushchyk ${ }^{1 *}$, Viktor V Novytskyy ${ }^{1}$, Igor P Babii ${ }^{2}$, Nadiya G Lushchyk², Olena V Babyuk², \\ Valentina $V$ Leonova², Ivanna I Legka ${ }^{3}$
}

From EPMA-World Congress 2013

Brussels, Belgium. 20-21 September 2013

\section{Scientific objectives}

Problems of psychoneurological patients' treatment always were and remain actual one as the nervous system's structure is complicated and treatment results are sometimes unpredictable [1]. Today new knowledge and intellectual technologies enable to reconsider generally accepted approaches.

\section{Results interpretation}

The Veritas Research Center has made the comparative analysis of standard and multidisciplinary approaches to treatment of 724 psychoneurological patients, who were treated and rehabilitated in the Clinic of Healthy Vessels. $78 \%$ had psychosomatic disorders, $63 \%$ of cases required psychotherapy, $47 \%$ - psychocorrection, $38 \%$ - psychospeech correction, $83 \%$ - motion disorders. $23 \%$ of patients had lasting patterns of psychological guidelines "on illness", aggravation, adjusting behaviour on the disease progress and block of the future vision. For the first month of treatment in the result of correction of the educed concomitant pathologies and rehabilitation the treatment effect has grown on $15-21 \%$ depending on the expressed psychoneurological lack. During the long-term rehabilitation for 3 months up to 1 year the treatment costs have reduced on $10-17 \%$ in comparing to standard approach and the treatment effect has grew on $75-83 \%[2,3]$. For a year of the individually oriented multidisciplinary rehabilitation and treatment $84 \%$ of serious non-curable patients with apallic

\footnotetext{
* Correspondence: u.lushchyk@gmail.com

${ }^{1}$ Research Center Veritas, 31 Obolonska Str., of. 9, Kyiv, 04071, Ukraine
}

Full list of author information is available at the end of the article syndrome, ICP, epilepsy has reached $5^{\text {th }}$ score of the Rancho Los Amigos Scale from the lower level [2,3].

\section{Outlook and expert recommendations}

According to the results of the conducted researches it is expedient to change the treatment algorithms for psychoneurological patients with the purpose of more rational use of costs and reaching greater effect, bringing the nervous system on the autoregulation level and self-control of neuronets, renewal of self-service and capacity.

\section{Authors' details \\ 'Research Center Veritas, 31 Obolonska Str., of. 9, Kyiv, 04071, Ukraine. ${ }^{2}$ The Clinic of Healthy Vessels, 4 Williams Str., Kyiv, 03191, Ukraine. ${ }^{3}$ Center for Innovative Medical Technologies Veritas IT Med, 4 Williams Str., Kyiv, 03191, Ukraine.}

Published: 11 February 2014

\section{References}

1. Lushchyk UB, Novytskyy W: Polyvector dynamic diagnostics of the vascular systems. A modern innovative medical technology: from local examinations to integrative comprehension of the whole system. Med Devices 2008, 3:64-67.

2. Lushchyk UB, Babii IP, Titenko TM, Novytskyy W, Stukalin VO, Lushchyk NG, Leonova W, Priz AM: Innovative vectors in neurorehabilitation. Logic and management of multidisciplinary approach in restorative medicine. In Macros. Volume 244. Kyiv; 2012.

3. Lushchyk UB, Novytskyy W, Alexeyeva TS, Francevich KA, Branytska NS: Analytical aspects of an individual hemodynamic correction in the angioneurology. In Istyna. Volume 130. Kyiv; 2006.

doi:10.1186/1878-5085-5-S1-A95

Cite this article as: Lushchyk et al: A project of harmonious health renewal in psychoneurological patients on the basis of the personalized algorithms for treatment and rehabilitation. EPMA Journal 2014 5(Suppl 1): A95. 